HEALING ARTS

Materia Medica

The Journey

\section{Siddharth Sridhar}

Queen Mary Hospital, Hong Kong, People's Republic of China.

"I am afraid I have bad news."

And so, with a clutch of well-prepared words, are life's most painful journeys begun. You both look at me, uncomprehending, a blank expression on your fresh, young faces. You remind me of a boy and a girl lost at a carnival, looking around for hands to hold.

You leave my office. Thoughts bubble over in his naïve mind as he takes your hand in his. He tells you that you will get through this. His voice admits no doubt as he wages eternal warfare on the foe inside you. But you don't really feel his hand in yours, do you? All your sensations are subdued to a pallid sepia. All your actions seem forced.

I watch you both through my window. I think.

You are back in a week's time. When I greet you, you smile. The sadness flees to your eyes.

I outline my plan of treatment. A scientific fervor grips the two of you as you bombard me with questions. Metastasis. Mutation. Target therapy. Oncogene. The two of you roll the unfamiliar words in your mouth, getting them to fit into the mold of everyday usage. I am swept by your enthusiasm, elated at the chance to give concrete answers to your straightforward questions. For all your questions are straightforward. It is as if you have a tacit, instinctual fear of ambiguities.

I understand this. I know them better than you. I fear them too.

Yet another week goes past, a bevy of preparation for the battle ahead. I learn from him about your Web searches and support groups. I am glib about the importance of mental preparation. I desperately wish I could believe my own words. I make amends by writing prescriptions for multivitamins, anti-emetics and painkillers. A pharmacopeia of escorts for the battalion I'm sending into your veins.

The next day dawns. He watches the drip stand intently as the tiny drops dribble out of a black bag into your veins. Every five minutes, he asks you how you feel. Not too bad, you answer him. You're both elated; the challenge is out, the first baby step on a road surely leading to recovery. Surely.

Published online March 10, 2015
I watch through the blinds.

Perhaps you are in that oh-so-slim band of miracles.

Perhaps you are meant to live forever.

Three months later, you sit before me, his hands on your shoulder. You wear a bandana now, colored bright pink. I tell you that the interim scans look promising. A truce, if not a rout. You smile as I unfold my plans for three more courses. You look at me roguishly and ask me what I have against your hair.

"You know we really can't afford to be laissez-hair at this stage," I quip. The two of you laugh.

I laugh as well.

Three months later, you are back in the chair. A grey bandana today. Hollowed cheeks. He has his hand on your shoulder again. Like an old man holding a crutch. He is changed too-a general deflation. I have just told you that your tumor markers are rebounding. The demon within you is counter-attacking. I slide quickly into plans involving wellchosen words: 'rescue, salvage, second-line'.

You look at me. You are about to ask me about an ambiguity, aren't you? I stop you with my eyes, not so much for my sake as his.

You lie on the bed in a fever, too exhausted to wake at my soft footsteps. I talk to him about how you are feeling. His eyebrows are slightly raised. Two thin furrows crease the middle of his forehead. He looks slightly dazed. I read his thoughts, so easily, so fluently; his mind is an open book written in a language that I have no wish to be literate in. You wake and he rushes to your side. I summon a smile, but end up with the same expression as his.

You look at me.

J Gen Intern Med 30(8):1231-2

DOI: $10.1007 /$ s11606-015-3268-8

(C) Society of General Internal Medicine 2015 
You can read me like an open book too, can't you?

One more week goes by and the latest scans are in.

I have failed you. We have lost.

One tear, just one, rolls down your face. He folds his hands, hugging himself tight. I look at the ground. He thanks me for everything I have done for you. I mumble something, an empty vessel of sound.

The last scene now.

You are there on the bed, but then again you are not. He stares ahead, once again the boy lost at the fair. The crowds mill around him. Ferris wheel, merry-go-round, cotton candy, clowns, chaos.

You wake briefly and look at him.

You're the lucky one here. You know that, don't you?

We have reached a parting of the ways. You take one road, he takes the other. I walk back slowly to where we started from: a lonely guide for a lonely road.

Corresponding Author: Siddharth Sridhar, Queen Mary Hospital, Hong Kong, People’s Republic of China (e-mail: sid8998@gmail.com). 